\title{
Design of Internship Information Systems Using Prototyping Method in PT. Gramedia Asri Media
}

\author{
Fransiska Wahyuning Kurniawati ${ }^{1}$, Christ Rudianto ${ }^{2}$, Augie David Manuputty ${ }^{3}$ \\ 1,2,3 Program Studi Sistem Informasi, Universitas Kristen Satya Wacana, Jawa \\ Tengah, Indonesia \\ Email:1682016088@student.uksw.edu, 2chris.rudianto@uksw.edu, \\ 3augie.manuputty@uksw.edu
}

\begin{abstract}
Human Resources (HR) is one of the important things that determine the success of a company's services, one of the things done to prepare a good HR is to launch a Job Training (PKL) program or also known as an internship. PT. Gramedia Asri Media became one of the companies that implemented the apprenticeship program, but the existing apprenticeship program was still carried out manually by distributing information to tertiary institutions via email. The results of this study are an apprenticeship information system design as a reference for making the system so that the apprenticeship process can be carried out in only one system from the dissemination of information to solving administrative problems related to finance and the need for an apprenticeship approval document. The system development method used in it is the prototyping method that starts from analyzing user needs to creating a User Interface (UI). The apprenticeship information system makes the apprenticeship process more effective both in the registration and internship process data contained therein.
\end{abstract}

Keywords: Information System, Internship, Human Resources, Prototyping Method, User Interface, .

\section{PENDAHULUAN}

Sejalan dengan perkembangan teknologi yang terjadi saat ini mendorong perusahaan untuk semakin meningkatkan kualitas layanan yang dimiliki, salah satu hal penting yang menjadi penentu kualitas layanan dan kinerja yang ada di sebuah perusahaan adalah ketersediaan Sumber Daya Manusia (SDM) dengan kualitas dan pengalaman yang memadai. Saat ini banyak perusahaan yang mulai membangun kerjasama dengan perguruan tinggi yang ada di Indonesia, salah satu tujuannya yaitu untuk meningkatkan kualitas SDM agar mampu menjadi SDM yang terampil di segala bidang melalui program magang, karena nantinya apabila kinerja yang dilakukan peserta magang berpotensi baik maka memungkinkan untuk direkrut menjadi karyawan, selain itu, magang juga menjadi salah satu syarat untuk dapat mengambil langkah selanjutnya dalam proses pendidikan di beberapa perguruan tinggi. Aktivitas magang sendiri telah diatur dalam Peraturan 
Menteri Tenaga Kerja dan Transmigrasi Republik Indonesia Nomor Per.22/MEN/IX/2009 Tentang Penyelenggaraan Pemagangan di Dalam Negeri. Keuntungan lain yang diperoleh perusahaan melalui magang yaitu memiliki SDM yang mempunyai potensi namun dengan upah kerja yang lebih sedikit sehingga kinerja baik namun dengan pengeluaran yang kecil.

PT.Gramedia Asri Media merupakan salah satu perusahaan yang menjalankan program magang dengan bekerjasama bersama beberapa perguruan tinggi, namun sejauh ini dalam proses magang yang dilakukan oleh PT.Gramedia Asri Media masih menggunakan metode manual dengan proses administrasi panjang yang mengharuskan calon peserta magang untuk datang langsung ke perusahaan. Hal ini tentu sangat memakan banyak waktu dan tenaga bagi karyawan serta untuk mahasiswa yang tinggal di wilayah jauh akan menghabiskan biaya lebih untuk bisa sampai di perusahaan, sehingga memperkecil minat mahasiswa yang berada di wilayah jauh untuk mengikuti magang di PT.Gramedia Asri Media. Dari segi administrasi data dan pengarsipan pun, berkas masih diolah menggunakan Excel yang berpotensi menimbulkan kesalahan pencatatan data dan sangat rentan terhadap risiko kehilangan dan kerusakan data.

Berdasarkan hal tersebut di atas serta mengingat perkembangan teknologi yang semakin pesat maka perlu dilakukan sebuah pembaruan terhadap sistem magang yang ada sehingga dapat memberikan kemudahan bagi kedua pihak, teknologi yang berkembang saat ini dirasa mampu untuk menjadi solusi terkait permasalahan tersebut. Sistem informasi akan membantu mahasiswa yang berada di wilayah jauh untuk tetap dapat mengikuti pendaftaran hingga urusan administrasi dari wilayah masing-masing. Selain itu, dari segi pengarsipan data tentu akan memperkecil penggunaan kertas dan risiko kehilangan data. Dari uraian permasalahan diatas, pada perancangan ini akan dibangun sebuah sistem informasi magang dengan mempertimbangkan sistem magang sebelumnya di PT.Gramedia Asri Media menggunakan metode prototyping. Melihat dari PT.Gramedia Asri Media sendiri sebelumnya pernah menerapkan sistem magang berbasis online namun sistem yang dibuat saat itu kurang sesuai dengan kebutuhan user dan proses bisnis magang yang dijalankan sehingga tidak dipakai kembali., aspek kemudahan dan kenyamanan dalam penggunaan sistem informasi magang menjadi salah satu fokus penting yang diperhatikan sehingga metode prototyping dirasa sesuai karena prototyping memungkinkan pembangunan sistem yang cepat dengan tetap memperhatikan kebutuhan user. 
Tujuan yang ingin dicapai dari penelitian ini yaitu mampu memberikan gambaran mengenai sistem informasi magang untuk pembangunan sistem kedepannya. Selain itu, memberikan solusi terkait permasalahan administrasi data yang ada dengan membuat penyimpanan menjadi lebih tertata menggunakan database sehingga meminimalisir terjadinya kehilangan data dan proses pencarian data dapat dilakukan lebih cepat serta mempermudah dalam penyajian informasi agar mahasiswa dapat mengetahui informasi mengenai program magang dengan lebih mudah dan bisa diakses ketika terhubung dengan internet dimanapun dan kapanpun. Manfaat yang diperoleh dengan adanya jurnal mengenai perancangan sistem informasi magang yang dilakukan di PT.Gramedia Asri Media ini akan menjadi referensi untuk memperkuat pembahasan dan perancangan sistem informasi dengan metode serupa yang telah dibahas dalam perancangan sebelumnya dan dapat digunakan sebagai acuan untuk pembangunan sistem kedepannya.

\section{METODOLOGI PENELITIAN}

Membahas mengenai metodologi yang digunakan di dalam perancangan sistem informasi magang ini tidak jauh berbeda dengan metodologi yang banyak digunakan di dalam perancangan terdahulu, hanya saja hasil akhir yang dibuat merupakan pengembangan dari hasil perancangan sistem informasi yang serupa sebelumnya. Di dalam perancangan sistem informasi magang ini menggunakan metode prototyping yang memungkinkan pembangunan sistem dengan jangka waktu yang singkat namun tetap memperhatikan kebutuhan user karena model prototype yang ada akan dibahas terlebih dahulu dan dilakukan perbaikan apabila tidak sesuai dengan kebutuhan user. Selain itu juga digunakan CodeIgniter framework untuk pengembangan sistem. CodeIgniter menerapkan Model View Controller (MVC) yang membangun sistem dengan memisahkan proses yang terjadi didalam sistem dengan tampilan yang diakses oleh user (Azdy, 2016). (Pradipta et al., 2015) berpendapat bahwa model prototype dihasilkan dengan beberapa langkah dan prosedur yang harus dilakukan diantaranya yaitu:

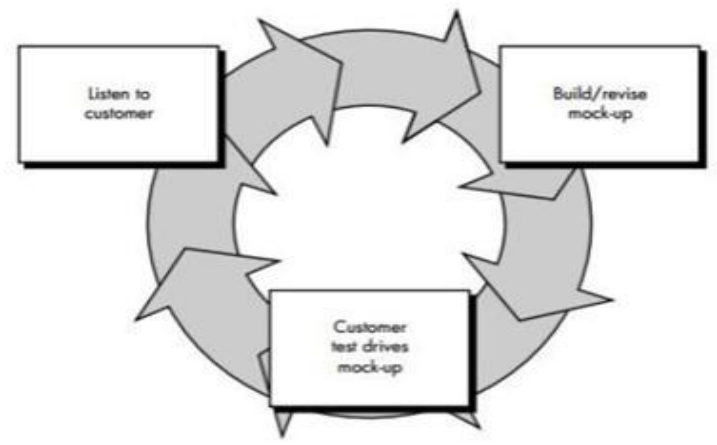

Gambar 1 Prototyping Model oleh Khosrow-Pour 2005 
1. Pengumpulan kebutuhan User (User Requirement)

Pada tahap pertama ini dilakukan analisa kebutuhan user melalui identifikasi permasalahan yang ada dengan pengumpulan data dan kesimpulan melalui wawancara dan observasi bersama dengan bagian terkait, dalam hal ini adalah manager Divisi Reqruitment yang ada di PT.Gramedia Asri Media.

2. Pembangunan Prototype

Pada tahap kedua ini dilakukan pembangunan prototype berupa perancangan sistem atau desain sistem informasi yang akan dibuat. Perancangan sistem informasi dibuat menggunakan beberapa perangkat lunak sesuai dengan tujuan dan fungsi yang akan dibentuk.

3. Evaluasi Prototype

Pada tahap ketiga ini dilakukan evaluasi bersama user terkait model prototype sementara yang telah dibuat. Evaluasi dilakukan dengan cara bertemu user secara langsung kemudian menjelaskan setiap proses dan penggambaran yang ada, jika user setuju dengan model prototype yang telah dibuat maka akan dilanjutkan ke tahap pengembangan berikutnya namun jika user memiliki masukan atau saran terkait model prototype sistem informasi yang ada maka disesuaikan dengan kebutuhan yang diinginkan oleh user.

\section{HASIL DAN PEMBAHASAN}

Pada bagian ini akan dijelaskan mengenai hasil dan pembahasan secara lebih rinci, hasil disajikan dalam gambar sehingga lebih mudah dipahami. PT. Gramedia Asri media pernah mengembangkan sistem informasi magang sebelumnya namun sistem yang ada kurang efektif dikarenakan ketersediaan database yang tidak memadai dan tampilan UI yang terbilang rumit untuk dipahami serta layanan yang terdapat didalamnya belum lengkap sehingga sulit untuk dioperasikan. Untuk itu, saat ini dilakukan pengembangan kembali terhadap sistem tersebut dengan menggunakan metode prototyping yang mengutamakan kemudahan dan kenyamanan user dengan kualitas yang lebih memadai dan layanan yang lebih lengkap sehingga kedepannya dapat memberikan dampak yang lebih baik bagi keberlangsungan proses bisnis dan program magang yang ada di perusahaan.

\subsection{Analisa Kebutuhan User}

Dari hasil identifikasi ditemukan bahwa beberapa proses bisnis yang ada di PT.Gramedia Asri Media sebagian besar sudah dibuat ke dalam sistem namun 
proses magang sendiri belum menerapkan hal tersebut dikarenakan beberapa kendala sehingga saat ini dilakukan kembali pengembangan terkait sistem informasi magang. Dalam metode prototyping, tahapan pertama yang harus dilakukan adalah pengumpulan data kebutuhan user yakni informasi dari unit/bagian perusahaan yang berkaitan dengan sistem yang akan dirancang. Penulis melakukan analisis kebutuhan fungsional, berkaitan dengan apa saja yang dapat dilakukan oleh admin dan user (peserta magang) serta hal penting yang harus ada di dalam sistem magang yang akan dibuat.

1. Admin (Divisi Reqruitment)

a. Data Profil

Dapat melihat dan melakukan update profil pribadi.

b. Data Seleksi Magang

Dapat melihat data peserta yang mengikuti seleksi magang, mengubah isi formulir pendaftaran dan membuat pengumuman terkait seleksi magang.

c. Data Peserta Magang

Dapat melihat data peserta yang sudah diterima magang dan menghapus data peserta magang yang sudah selesai.

d. Data Kehadiran Peserta Magang

Dapat melihat dan download daftar hadir peserta magang yang nantinya digunakan untuk pencairan uang saku.

e. Data Evaluasi Peserta Magang

Dapat melakukan input hasil evaluasi peserta magang yang diberikan oleh mentor kepada tiap peserta magang.

f. Data Uang Saku

Dapat melakukan input jumlah uang saku yang diterima oleh peserta magang dan melakukan update mengenai status pencairan uang saku.

2. User (Peserta Magang)

a. Data Profil

Dapat melihat profil pribadi.

b. Data Seleksi Magang

Dapat melakukan pengisian formulir untuk melakukan pendaftaran magang.

c. Data Peserta Magang

Dapat melakukan input data pribadi dan melakukan update data pribadi.

d. Data Kehadiran Peserta Magang 
Dapat melakukan input kehadiran beserta dengan tanggal dan waktu ketika datang dan pulang magang.

e. Data Penilaian

Dapat melihat hasil penilaian yang telah diberikan oleh mentor dan mendownload sertifikat penilaian.

f. Data Uang Saku

Dapat melihat status pencairan uang saku.

\subsection{Pembangunan Prototype}

Setelah diperoleh data kebutuhan user, selanjutnya data yang ada akan diperjelas kembali dalam sebuah prototype sistem dengan menerapkan rancangan menggunakan Unified Modeling Language (UML) dan MVC yang memisahkan proses di dalam sistem dengan tampilan yang diakses oleh user, berikut gambaran prototype sistem yang telah dibuat :

\subsubsection{Kebutuhan Perangkat}

Diagram ini dibuat untuk menggambarkan perangkat-perangkat apa saja yang harus dipenuhi untuk pembangunan sistem nantinya.

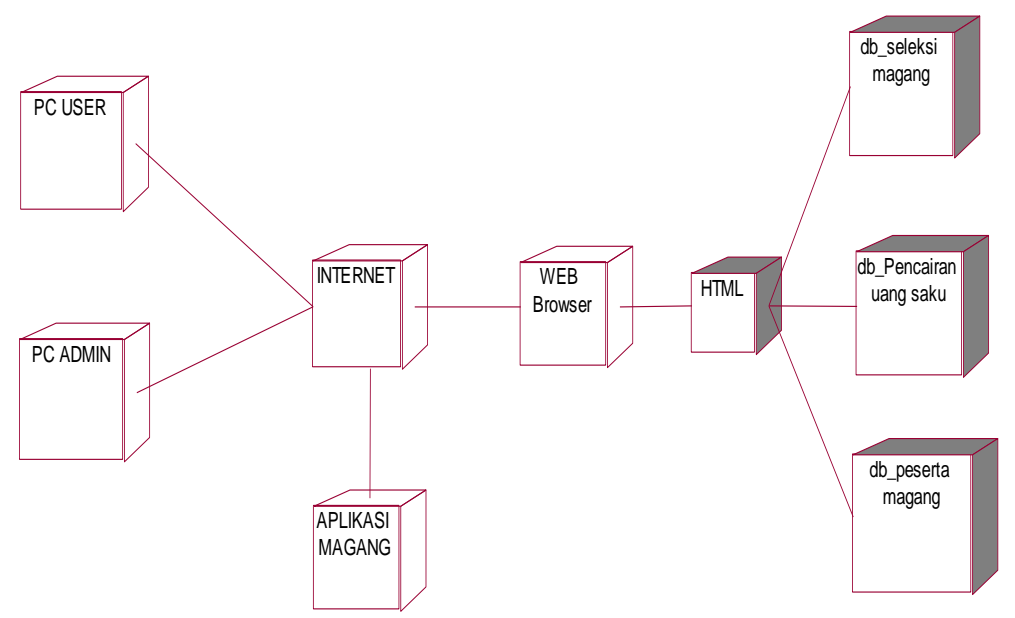

Gambar 2. Deployment Diagram

\subsubsection{Entity Relationship Diagram (ERD)}

ERD dibuat untuk menggambarkan hubungan antar entitas dan apa saja atribut yang terdapat pada setiap entitas, berfungsi untuk memudahkan dalam pembuatan tabel dan database dalam sistem nantinya. 
Vol. 2, No. 1, March 2020

p-ISSN: 2656-5935 http://journal-isi.org/index.php/isi e-ISSN: 2656-4882

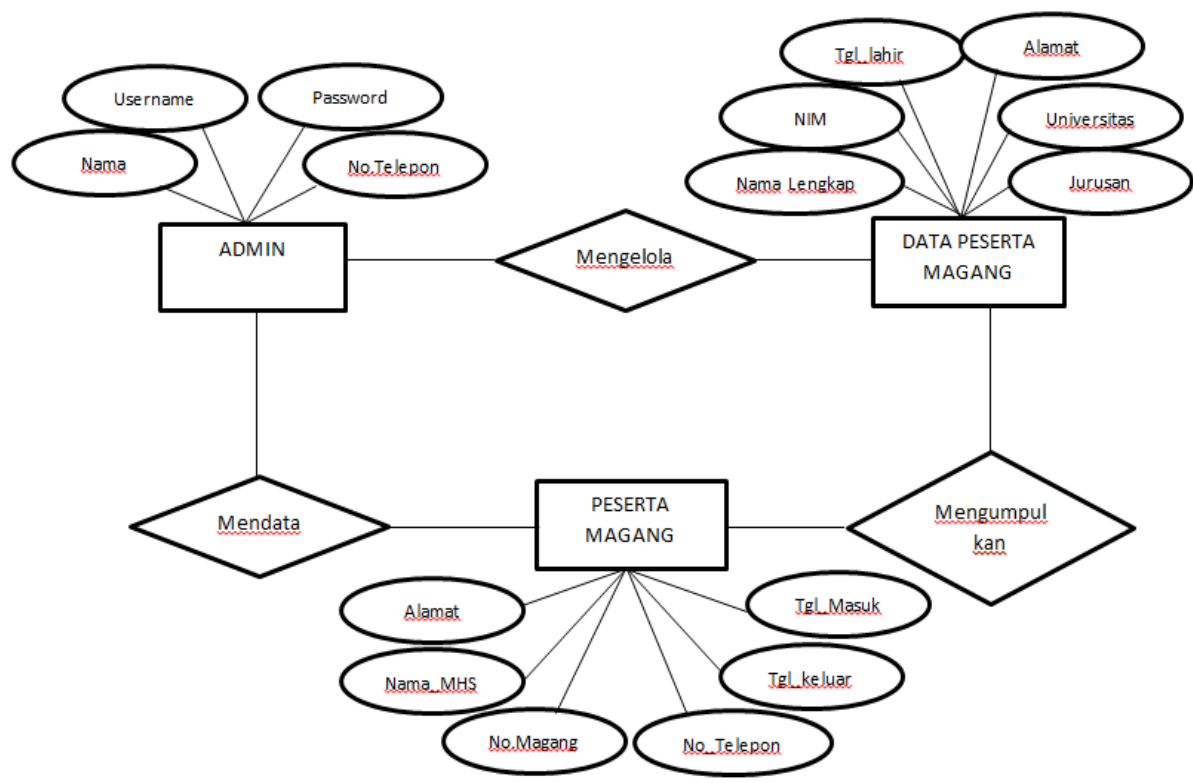

Gambar 3. ERD Diagram

\subsubsection{Rancangan UML}

Diagram ini berfungsi menggambarkan mengenai aktor siapa saja yang terlibat dalam penggunaan sistem dan hak akses apa saja yang dimiliki. Dalam sistem ini aktornya adalah Admin dan User.

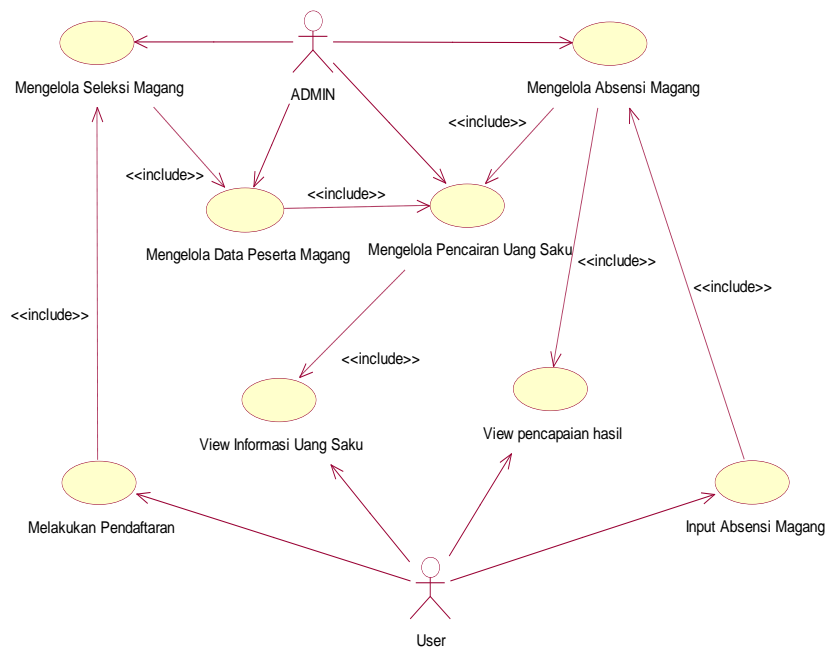

Gambar 4. Use Case Diagram 
Diagram ini dibuat untuk menggambarkan mengenai hubungan antar database dan unit/bagian apa saja yang bertanggungjawab sebagai acuan untuk pembuatan tabel-tabel yang akan dirancang dalam sistem, sebagai berikut.

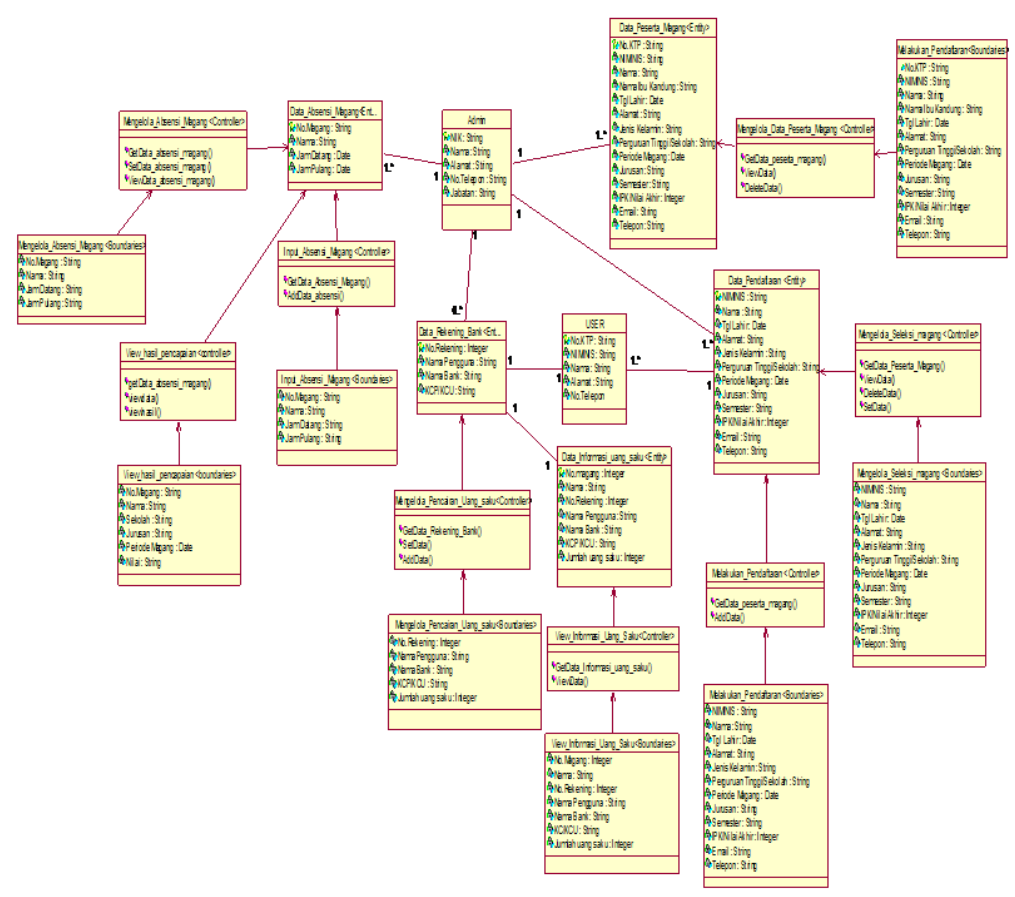

Gambar 5. Class Diagram

\subsubsection{Tampilan Antar Muka Sistem Informasi}

1. Tampilan Web Admin

a. Menu Utama Admin

Menu Utama Admin adalah menu yang muncul ketika Login yang dilakukan admin berhasil, berisi pilihan-pilihan submenu yang akan dijalankan oleh admin pada Sistem Informasi Magang, yang terdiri dari : data seleksi magang, data peserta magang, data kehadiran peserta magang, data evaluasi peserta magang dan data uang saku peserta magang. Tampilan menu utama dibuat user friendly berupa icon sehingga yang menggunakan sistem lebih mudah dalam mengoperasikan dan tidak cepat merasa jenuh dengan menu yang ada. 
Vol. 2, No. 1, March 2020

p-ISSN: 2656-5935 http://journal-isi.org/index.php/isi e-ISSN: 2656-4882

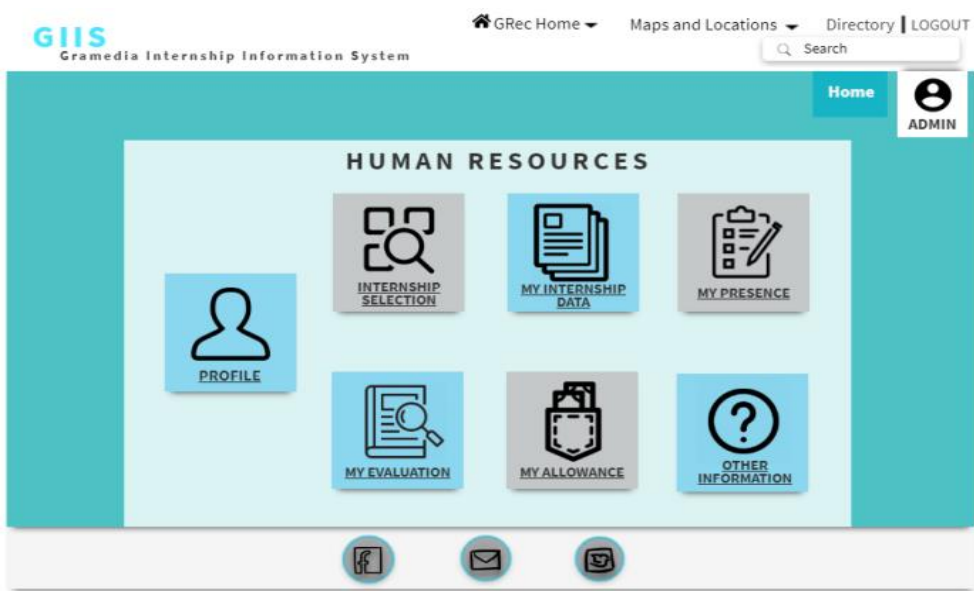

Gambar 6. Tampilan Menu Utama Admin

b. Menu Seleksi Peserta Magang

Menu seleksi peserta magang berisi data-data beserta berkas calon peserta yang melakukan pendaftaran magang sebelum akhirnya diterima untuk magang, berfungsi untuk mempermudah pendaftaran calon peserta magang agar tidak perlu datang secara langsung ke perusahaan dan menyimpan data pribadi calon peserta magang sehingga ketika dibutuhkan dapat diperoleh dengan lebih mudah dan cepat serta memudahkan dalam melakukan seleksi calon peserta magang.

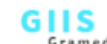

त GRec Home- Maps and Locations - Directory | Logour

Gramedia Internship Information system

Search

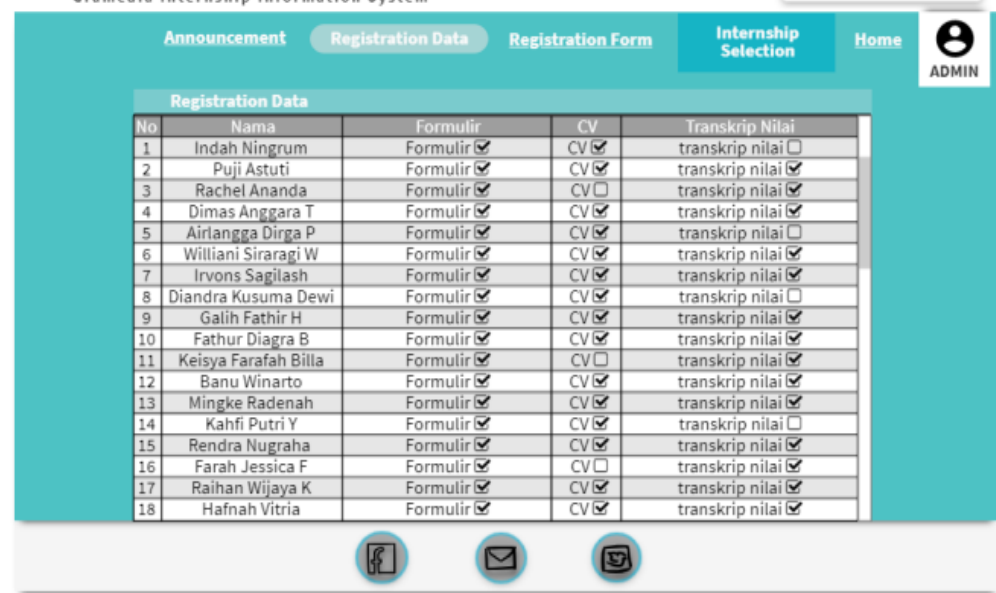

Gambar 7. Tampilan menu Seleksi Peserta Magang 
Vol. 2, No. 1, March 2020

\section{c. Menu Kehadiran Peserta Magang}

Menu Kehadiran peserta magang berisi daftar hadir peserta magang setiap hari selama proses magang berlangsung, menu ini berfungsi untuk melihat keaktifan dari tiap peserta dan menjadi acuan untuk pencairan uang saku serta penilaian setiap bulannya.

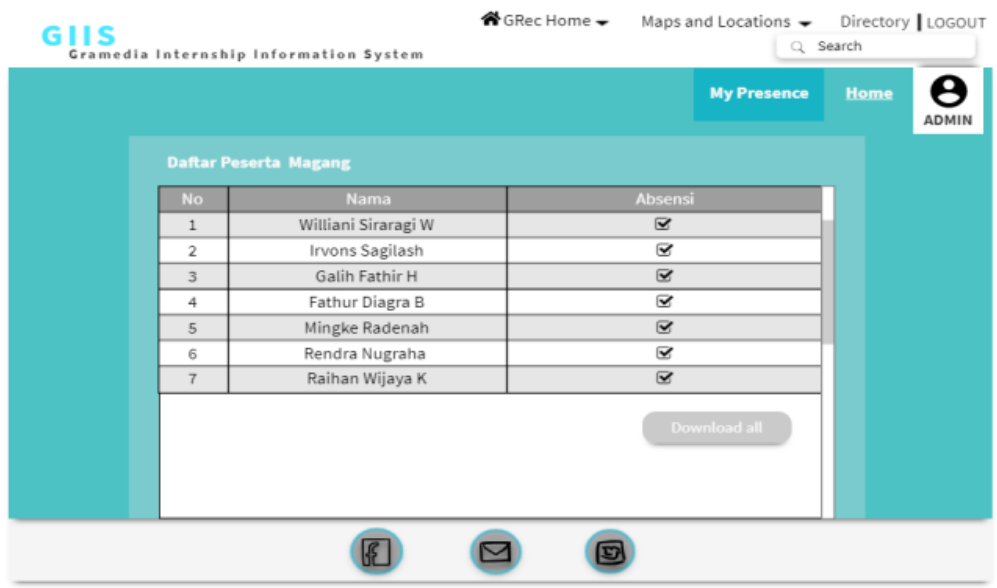

Gambar 8. Tampilan menu Kehadiran Peserta Magang

d. Menu Pencairan Uang Saku

Menu pencairan uang saku berfungsi untuk menampilkan status pencairan uang saku peserta magang dengan melihat daftar hadir sebagai acuan, berfungsi agar peserta magang tidak perlu bertanya pada bagian keuangan mengenai status pencairan uang saku selain itu juga mempermudah dalam perekapan data laporan keuangan.

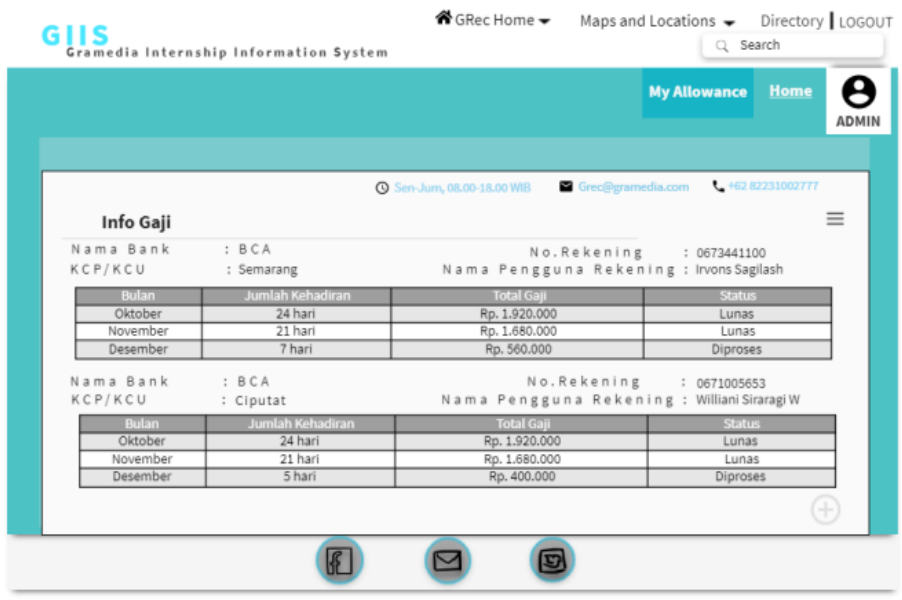

Gambar 9. Tampilan Menu Pencairan Uang Saku 


\section{Tampilan Web User}

Sebelum diterima untuk magang, peserta magang harus melakukan pengisian formulir pendaftaran terlebih dahulu melalui web yang sudah disediakan, formulir pendaftaran ini berfungsi untuk memudahkan pendaftaran magang agar peserta tidak perlu datang secara langsung dan dapat mengirimkan berkas persyaratan melalui web pendaftaran.

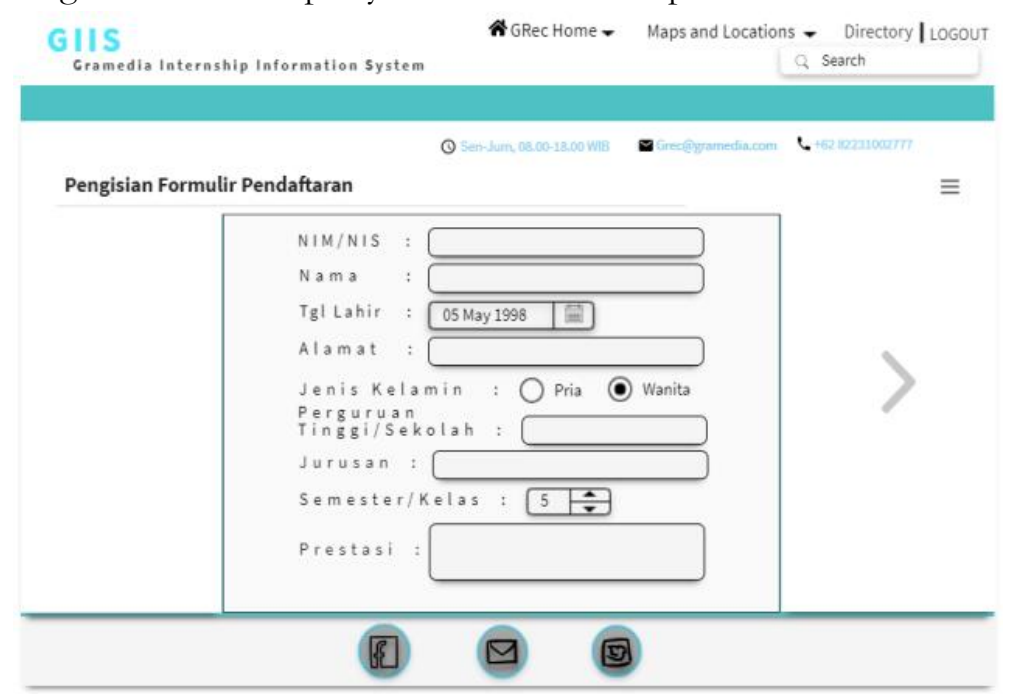

Gambar 10. Tampilan Pengisian Formulir Pendaftaran

3. Tampilan Android User

a. Menu Sign In dan Menu Utama Android User

Menu Sign In sistem android hanya bisa dilakukan oleh peserta yang telah diterima magang dan memperoleh no magang, berfungsi untuk memberikan batasan kepada pihak yang tidak berkepentingan agar tidak dapat mengakses dan mengolah data tanpa login terlebih dahulu dan mempermudah dalam pengelolaan administrasi selama program magang berlangsung. Menu Utama User berisi pilihan submenu yang dapat diakses oleh user berfungsi agar user dapat dengan mudah melakukan pengelolaan data dan perolehan informasi yang berkaitan dengan magang terdiri dari : data pribadi, data kehadiran magang, data penilaian dan data pencairan uang saku. 
Vol. 2, No. 1, March 2020
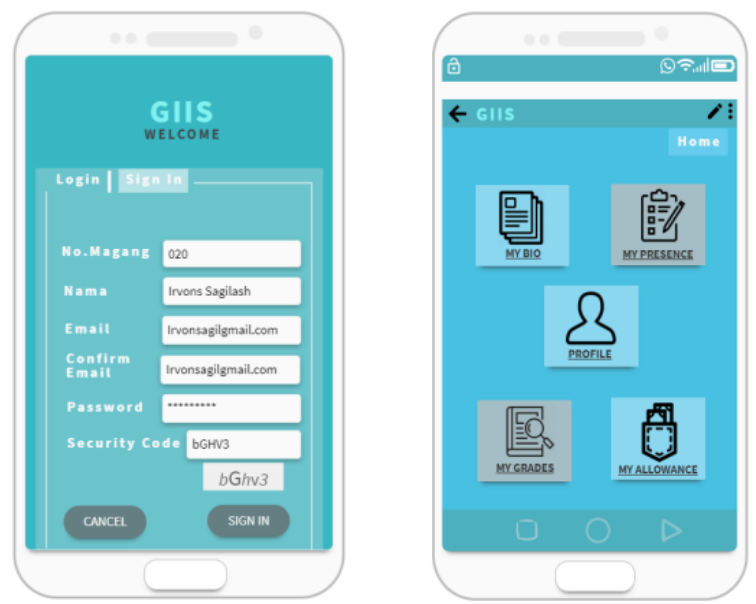

Gambar 11. Tampilan Sign In dan Menu Utama Android User

b. Menu Profil dan Data Pribadi

Menu Profil merupakan menu yang berisi data pengguna akun/sistem pada saat melakukan akses dan Menu data pribadi merupakan menu untuk melakukan pengisian data pribadi peserta magang secara lebih rinci kedua menu ini berfungsi untuk menyimpan data pribadi peserta magang sehingga ketika dibutuhkan, data bisa diperoleh dengan lebih mudah dan cepat.
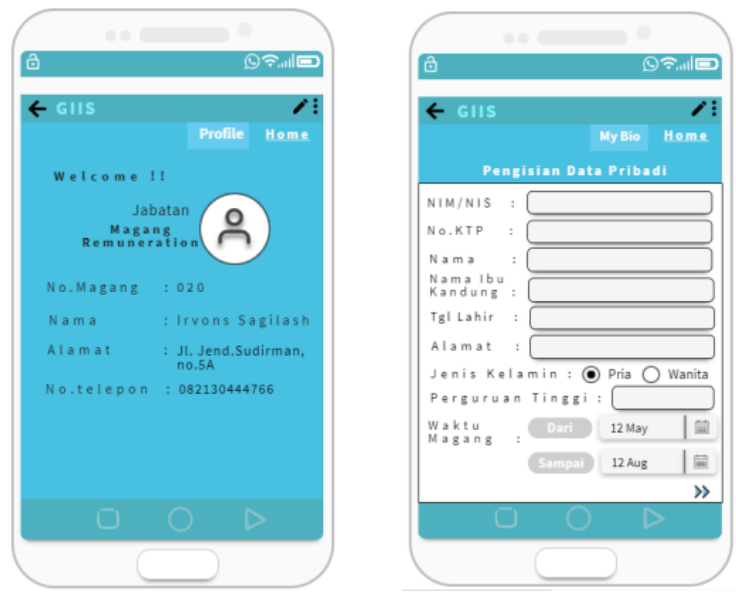

Gambar 12. Tampilan Menu Profil dan Data Pribadi

c. Menu Kehadiran dan Penilaian peserta magang

Menu kehadiran berfungsi untuk melakukan pengisian absensi sebagai bukti keaktifan peserta magang yang nantinya juga digunakan sebagai 
Vol. 2, No. 1, March 2020

acuan perolehan uang saku dan nilai magang, nilai magang dilihat dari kehadiran dan keaktifan kinerja yang dilakukan oleh peserta magang.
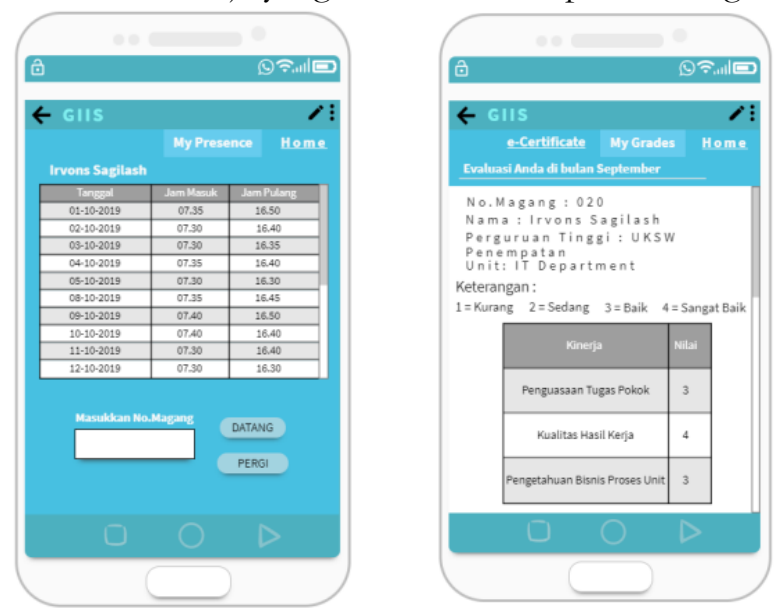

Gambar 13. Tampilan Menu Kehadiran dan Penilaian Peserta Magang

d. Menu Pencairan Uang Saku dan tampilan e-certificate peserta magang Menu pencairan uang saku berisi status uang saku tiap peserta magang yang berfungsi agar peserta magang dapat melihat jumlah dan status uang saku tanpa bertanya kepada bagian keuangan setiap bulannya dan hasil akhir dari program magang adalah sertifikat magang yang berisi penilaian secara keseluruhan selama program magang berlangsung, berfungsi untuk memberikan penghargaan kepada peserta magang sehingga peserta magang mengetahui pencapaian yang diperoleh, sertifikat yang ada berbentuk online agar mengurangi penggunaan kertas.
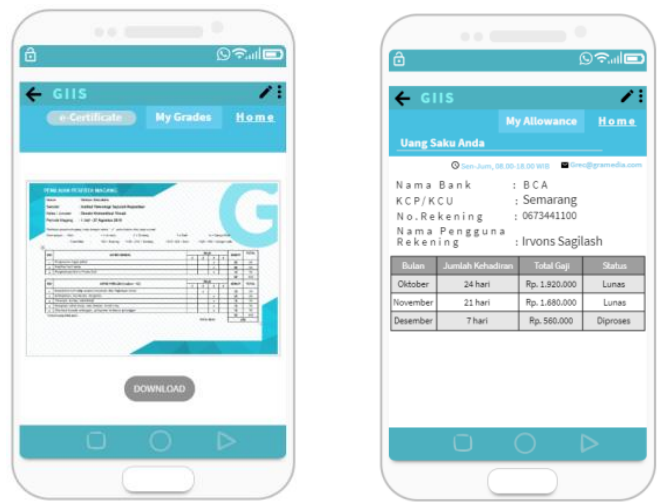

Gambar 14. Tampilan Menu Pencairan Uang Saku dan $e$-Certificate Peserta Magang 


\subsection{Evaluasi Prototype}

Dalam proses rancangan sistem informasi, hasil awal prototype dibuat berdasarkan informasi kebutuhan user yang kemudian dilakukan evaluasi prototype untuk mengetahui apakah prototype tersebut telah memenuhi kebutuhan user atau belum dengan mempresentasikan hasil prototype kepada unit/bagian terkait., apabila terdapat tampilan atau komponen yang tidak sesuai maka akan dilakukan perbaikan, namun jika model prototype yang dibuat sudah sesuai maka akan dilanjutkan ke tahapan berikutnya. Setelah dilakukan evaluasi prototype didapatlah perubahan-perubahan sampai akhirnya dapat memenuhi kebutuhan user.

\subsubsection{Prototype I}

Pada rancangan sistem informasi magang ini, setelah di evaluasi ada beberapa komponen yang tidak sesuai dengan yang diharapkan oleh user, seperti :

1. Background Sistem Informasi

Background sistem informasi dari prototype I ini tidak sesuai dengan yang diharapkan, karena warna yang terlalu cerah dan mengganggu pandangan mata ketika mengakses sistem sehingga prototype I yang awalnya berwarna biru muda diganti menjadi warna biru kehijauan.

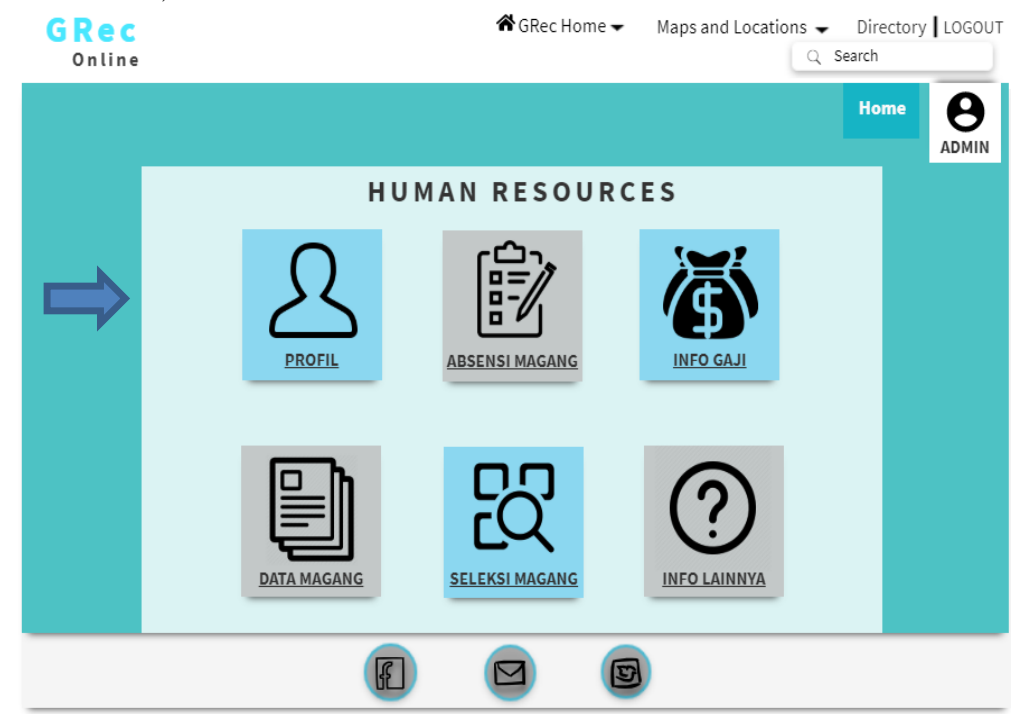

Gambar 15. Prototype I Menu Utama Admin

\section{Bahasa Menu Sistem Informasi}

Bahasa menu sistem informasi pada prototype I ini tidak sesuai dengan yang diharapkan, karena bahasa yang digunakan pada menu 
kurang menarik dan terlalu panjang yang sulit untuk diingat sehingga bahasa menu pada prototype I diganti menggunakan bahasa Inggris yang lebih modern, singkat dan mudah diingat oleh user.

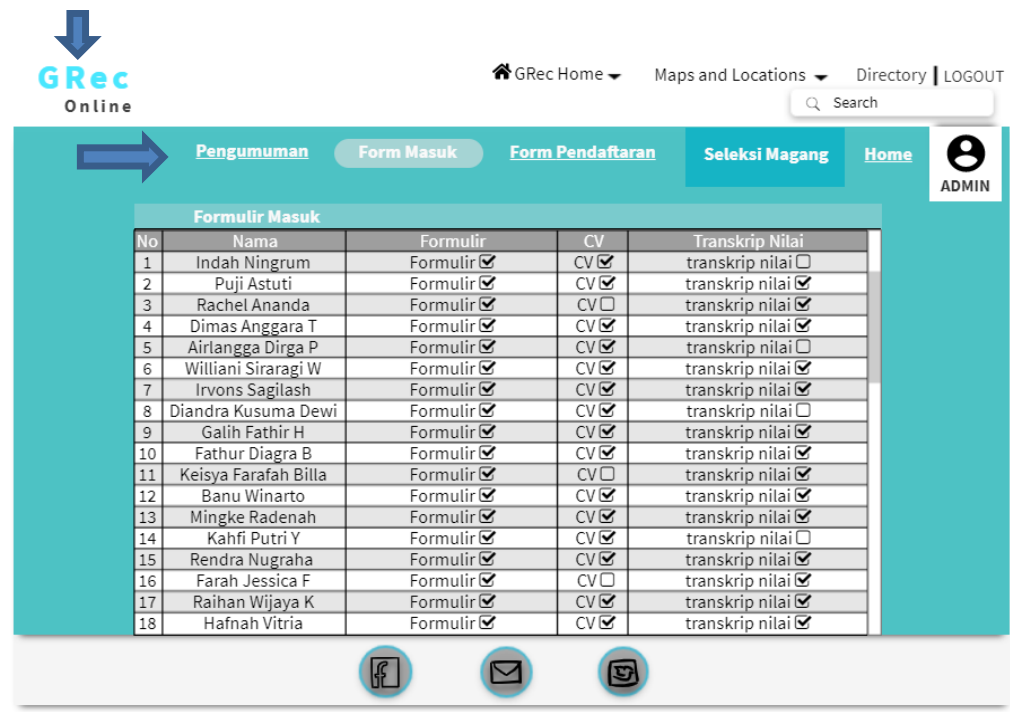

Gambar 16. Prototype I Bahasa Pada Menu

Setelah dilakukan beberapa perbaikan tersebut, akhirnya penulis kembali memaparkan hasil revisi dan diperoleh prototype akhir seperti yang telah dipaparkan pada bagian hasil dan pembahasan diatas.

\section{KESIMPULAN}

PT.Gramedia Asri Media merupakan perusahaan yang kompetitif sehingga perlu memiliki sistem informasi yang mampu bersaing, salah satunya yakni dengan membuat sebuah sistem untuk memudahkan program yang dijalankan tak terkecuali pemagangan. Dan setelah melewati beberapa tahapan perbaikan, prototype mengenai sistem informasi magang yang telah dibuat ini akhirnya dapat diterima user dengan baik. Melalui sistem informasi magang ini maka segala penyimpanan data dapat disimpan menggunakan database sehingga layanan administrasi bisa dilakukan dengan cepat dan tertata yang mampu meminimalisir terjadinya kehilangan data dan proses pencarian data yang lama, selain itu dengan adanya kemudahan dalam penyajian informasi, mahasiswa menjadi lebih mudah untuk mengetahui informasi mengenai program magang yang ada dan administrasi data bisa diakses dimana saja, sehingga program PT.Gramedia Asri Media khususnya program magang ini dapat mencapai tujuan yang diharapkan yakni mempermudah kedua pihak dalam melaksanakan program magang itu sendiri. 
Penulis menyadari dalam membuat perancangan ini masih terdapat banyak kekurangan sehingga perlu dilakukan pertimbangan dan testing terlebih dahulu sebelum sistem benar-benar dijalankan serta keamanan data juga menjadi hal penting yang perlu diperhatikan.

\section{DAFTAR PUSTAKA}

[1] Azdy, R. A. (2016). Aplikasi Penerimaan Mahasiswa Magang Berbasis Objek Pada Perum Bulog Divre Sumatra Selatan. Eksplora Informatika, 6(1), 33-43. https://eksplora.stikombali.ac.id/index.php/eksplora/article/view/102/85

[2] Pradipta, A. A., Prasetyo, Y. A., \& Ambarsari, N. (2015). Pengembangan Web E-Commerce Bojana Sari Menggunakan Metode Prototype. EProceeding of Engineering, 2(1), 1042-1056.http://libraryeproceeding.telkom university.ac.id/index.php/engineering/article/view/2726

[3] Wijayanti, D., Dwi Asworowati, R., \& Ananta, Y. K. (2018). Sistem Informasi Penerimaan Pengemudi Berbasis Web Dengan Metode Prototype: Studi kasus PT. Dinamika Makmur Sentosa Cikarang. IJCIT Indonesian Journal on Computer and Information Technology, 3(2), 176-185.

[4] Purnomo, D. (2017). Model Prototyping Pada Pengembangan Sistem Informasi. J I M P - Jurnal Informatika Merdeka Pasuruan, 2(2), 54-61. https://doi.org/10.37438/jimp.v2i2.67

[5] Lestari, N. (2019). Design of Information Systems for Food Distribution Control in LDPM Batutaba Sepakat. Journal of Information Systems and Informatics, 1(2), 77-86. https://doi.org/10.33557/journalisi.v1i2.9

[6] Hakim, L., \& Oktariandi, M. A. (2017). Perancangan Sistem Tracer Alumni Stmik Musi Rawas Berbasis Web Mobile. Jusim, 2(2), 108-116 